\title{
Economic and Politico-Economic Equivalence of Fiscal Policies
}

\author{
Martín Gonzalez-Eiras \\ Universidad de San Andrés* \\ Dirk Niepelt \\ SCG; U o Bern; IIES, SU; CEPR ${ }^{\dagger}$
}

February 15, 2008

\begin{abstract}
We consider intergenerational transfer policies that are equivalent in terms of the allocation they support, in particular pay-as-you-go financed policies on one hand and policies with explicit government debt on the other. We analyze the conditions under which political decision makers are indifferent between such "economically equivalent" policies, i.e., the conditions under which a policy constitutes a politico-economic equilibrium if an economically equivalent policy does. We apply our findings to results in the recent literature on politico-economic equilibria with social security. Our results imply that many other fiscal policies beyond the pure social security policies considered in those papers support politico-economic equilibria as well. We also discuss the implications of our results for social security reform.
\end{abstract}

KEYWORDS: Equivalent policy; intergenerational transfers; government debt; social security reform.

JEL Classification Code: E62, H55, H63.

\section{Introduction}

When political and economic decisions are made in an intertemporal setting, politicoeconomic equilibrium corresponds to the outcome of a dynamic policy game. In this game, economic and political decisions interact - current and future expected policy affects private sector decisions, while economic outcomes influence future policy choices. Due to

*Vito Dumas 284, B1644BID Victoria, Pcia. Buenos Aires, Argentina. E-mail: mge@udesa.edu.ar

${ }^{\dagger}$ P.O. Box 21, CH-3115 Gerzensee, Switzerland. E-mail: dirk.niepelt@iies.su.se ssvsde1.tex 
this complex interaction, researchers studying dynamic policy games often try to minimize the dimensionality of the state space and policy space in order to simplify the game as much as possible. For example, most politico-economic models of intergenerational transfers focus on social security transfers as the policy instrument, abstracting from deficits and government debt. As is well known, however, a given equilibrium allocation often can be sustained by various different fiscal policies (the Ricardian equivalence result is a special instance of this fact). Perhaps the best-known example in this context relates to the fact that an exogenous social security policy is equivalent to certain debt-plus-tax policies as far as the allocation they sustain is concerned-social security and debt-plustax policies are economically equivalent.

In this paper, we provide a general characterization of economic equivalence and analyze the conditions under which economic equivalence of a class of fiscal policies extends to the political sphere. More specifically, we first develop a general framework for the analysis of economically equivalent fiscal policies. We then proceed and analyze the conditions under which the economic equivalence extends to situations where policy is endogenous, i.e., chosen to maximize some political objective function. We derive sufficient conditions that guarantee that a particular policy supports a politico-economic equilibrium if an economically equivalent policy also supports a politico-economic equilibrium. These conditions relate to the choice sets of policy makers under the different policy regimes and are satisfied in many situations of interest.

We apply our findings to results in the recent literature on politico-economic equilibria with social security. As mentioned before, this literature often abstracts from government debt. Our results imply, that many other fiscal policies beyond the pure social security policies considered in those papers support politico-economic equilibria as well. However, politico-economic equilibria with social security that rest on trigger-strategy type enforcement mechanisms may not easily be reinterpreted as trigger equilibria with government debt. We also apply our results to shed light on the discussion of social security reform. Our results suggest that a regime switch from pay-as-you-go financed social security systems to systems with prefunding and government debt might not be neutral if the conditions of our equilibrium result are violated.

Besides the literature on politico-economic equilibria with social security (Cooley and Soares, 1999; Boldrin and Rustichini, 2000; Forni, 2005; Gonzalez-Eiras and Niepelt, 2008), our paper relates to the literature on the neutrality of government debt. Barro (1974) makes the first formal statement on the irrelevance of debt in a setting with infinitely lived agents and lump sum taxation. Sargent (1987) extends the neutrality result to environments with overlapping generations. Rangel (1997), Niepelt (2005) and Bassetto and Kocherlakota (2004) allow for distorting taxation; the former two papers also consider the implications for social security reform, conditional on exogenous policy.

The paper is structured as follows. Section 2 lays out the model. In sections 3 and 4, we derive the economic and political equivalence results, respectively. Section 5 contains the applications and section 6 concludes with a discussion of the implications for social security reform. 


\section{The Model}

We consider a discrete-time economy with time indexed by $t \in \mathcal{T}=\{0,1, \ldots\} .^{1}$ The economy is inhabited by a government, firms and/or "the rest of the world," and households. The latter are indexed by $i \in \mathcal{I}$. $\mathcal{I}_{t} \subseteq \mathcal{I}$ denotes the set of households alive in period $t$.

Let $x_{t}^{i}$ denote the vector of goods household $i$ purchases/sells in period $t$, and let $x_{t}$ denote the vector of aggregate purchases in the period. The vector $x_{t}^{i}$ might include the household's labor supply, purchases of various consumption and investment goods etc. Denote by $x^{i}$ the vector of household $i$ 's purchases over its life-time. ${ }^{2}$ Household $i$ 's purchases are admissible if they lie in some set $X^{i}$. Admissability requires, for example, that labor supply does not exceed the time endowment in the period. By convention, the first element in $x_{t}^{i}$ or $x_{t}$ refers to the numeraire.

Let $(q, r)$ denote the (pre-tax) price system in the economy. In particular, the vector $q_{t}$ denotes the period- $t$ prices of all goods in terms of the numeraire; and $r_{t, s}$ denotes the price of the numeraire in period $s$ in terms of the numeraire in period $t$, that is, the inverse of the interest rate between the two periods.

Let $g_{t}^{i}\left(x^{i}, q, r\right)$ denote the tax imposed on household $i$ in period $t .^{3}$ Taxes in period $t$ may depend both on the household's purchases/sales, $x^{i}$, and on the price system, $(q, r)$. For example, a labor income tax renders the tax function dependent on the product of $i$ 's labor supply in period $t$ (which is an element of $x^{i}$ ) and the hourly wage of the household in that period (which is an element of $q_{t}$ ). Note that taxes in period $t$ may depend on purchases in periods other than $t^{4}$ Let $g^{i} \equiv\left\{g_{t}^{i}(\cdot)\right\}_{t=i_{1}}^{i_{T}}$ where $i_{1}$ and $i_{T}$ denote the first and last period of $i$ 's lifetime, respectively. Denote the profile of tax functions across households by $g \equiv\left\{g^{i}\right\}_{i \in \mathcal{I}} .^{5}$

In their role as economic agents, households take prices and tax functions as given. The budget set of household $i, \mathcal{B}^{i}\left(q, r, g^{i}\right)$, then is given by

$$
\mathcal{B}^{i}\left(q, r, g^{i}\right)=\left\{x^{i} \mid \sum_{t=i_{1}}^{i_{T}} r_{i_{1}, t}\left(q_{t} \cdot x_{t}^{i}+g_{t}^{i}\left(x^{i}, q, r\right)\right) \leq 0\right\} .
$$

A government policy consists of a sequence of vectors of government purchases, a profile of tax functions imposed on firms and/or the rest of the world (tariffs), a profile $g$ of tax functions imposed on households, and sequences of government debt issuance and redemption. Let $b_{t+1}$ denote the amount of government debt issued in period $t$

\footnotetext{
${ }^{1}$ The extension to the stochastic case is immediate. Under the assumption that the number of contingencies in each period is finite, and with some slight adjustments in the notation, $t$ can alternatively be regarded as indexing the states of nature over time.

${ }^{2}$ And, in the stochastic case, across states of nature.

${ }^{3}$ Throughout the analysis, we assume that taxes (and government debt) are defined in terms of the numeraire good such that tax functions map household transactions into a scalar.

${ }^{4}$ With sequential policy choice of the form considered later, however, taxes may not depend on purchases in future periods.

${ }^{5}$ Typically, the tax functions imposed on households satisfy cross-sectional restrictions (in particular, $g_{t}^{i}(\cdot)$ might be identical to $g_{t}^{j}(\cdot)$ for all $\left.i, j \in \mathcal{I}\right)$. While we do not impose such restrictions, the analysis allows for them.
} 
and outstanding at the beginning of period $t+1$ (to keep the notation simple, we only consider short-term debt). Let $v_{t}$ denote the price of this debt. When issuing new debt $b_{t+1}$ in period $t$, the government therefore raises funds equal to $v_{t} b_{t+1}$. Let $z_{t+1}$ denote the repayment rate on debt maturing in period $t+1$.

The policies we consider in the following differ with respect to the profile $g$ of tax functions imposed on households as well as the government debt sequences $(b, z)$, but they do not differ as far as other taxes or government consumption is concerned. For simplicity, and without loss of generality, we assume that these other taxes as well as government consumption are equal to zero. A policy $p$ thus has the form $p=(g,(b, z))$.

A competitive equilibrium conditional on a set of initial conditions ${ }_{0} x$ and a policy $p$ consists of a price system $(q, r)$, debt prices $v$, household choices $x^{i} \in X^{i}$ for all $i \in \mathcal{I}$, and choices by firms and/or the rest of the world such that (i) $x^{i}$ is optimal with respect to $\mathcal{B}^{i}\left(q, r, g^{i}\right)$ for all $i \in \mathcal{I}$; (ii) choices by firms and/or the rest of the world are optimal with respect to their relevant budget sets defined, among others, by $(q, r)$; (iii) choices by households and firms and/or the rest of the world satisfy the resource/production possibilities constraints; (iv) the government budget constraints

$$
\sum_{i \in \mathcal{I}_{t}} g_{t}^{i}\left(x^{i}, q, r\right)=b_{t} z_{t}-v_{t} b_{t+1} \text { for all } t \in \mathcal{T}
$$

as well as the no-Ponzi-game condition are satisfied; and (v) the debt market clears (with investors forming rational expectations),

$$
v_{t}=r_{t, t+1} z_{t+1} \text { for all } t \in \mathcal{T} \text {. }
$$

\section{Economic Equivalence}

Conditional on a price system $(q, r)$, we can define the net tax imposed on household $i$, $n^{i}\left(x^{i}, q, r\right)$, as the present discounted sum of the relevant (gross) taxes:

$$
n^{i}\left(x^{i}, q, r\right) \equiv \sum_{t=i_{1}}^{i_{T}} r_{i_{1}, t} g_{t}^{i}\left(x^{i}, q, r\right)
$$

If, conditional on the price system $(q, r)$, two sets of tax functions, $g^{i}$ and $g^{i^{\prime}}$ say, are associated with the same net tax function $n^{i}(\cdot, q, r)$,

$$
\sum_{t=i_{1}}^{i_{T}} r_{i_{1}, t} g_{t}^{i}\left(x^{i}, q, r\right)=\sum_{t=i_{1}}^{i_{T}} r_{i_{1}, t} g_{t}^{i^{\prime}}\left(x^{i}, q, r\right) \text { for all } x^{i} \in X^{i}
$$

then $g^{i}$ and $g^{i^{\prime}}$ imply identical budget sets $\mathcal{B}^{i}\left(q, r, g^{i}\right)$. To the extent that households can freely adjust their savings and do not value policy per se (beyond its effect on the budget set), the net tax function therefore summarizes the effect of policy on household welfare, as stated in Lemma 1. 
Assumption 1. Households can borrow or lend at the interest rates $r$. Households' preferences do not depend on policy or prices beyond the effect of policy and prices on budget sets.

Lemma 1. Under Assumption 1, and holding the price system fixed, two sets of gross tax functions associated with the same net tax functions yield the same optimal household choices.

Lemma 1 states a "partial equilibrium indifference" result according to which households are indifferent between two tax policies as long as these policies are associated with the same price system and net tax functions. This partial equilibrium result readily extends to general equilibrium.

Assumption 2. Firms' objectives do not depend on policy or prices beyond the effect of policy and prices on firms' budget sets.

Under Assumptions 1 and 2, a generalized version of the Ricardian equivalence proposition holds.

Proposition 1. Consider a policy $p=(g,(b, z))$, a price system $(q, r)$, debt prices $v$, household choices $\left\{x^{i}\right\}_{i \in \mathcal{I}}$, and firm choices that constitute a competitive equilibrium. Let $p^{\prime}=\left(g^{\prime},\left(b^{\prime}, z^{\prime}\right)\right)$ be another, "economically equivalent" policy satisfying the following conditions:

$$
\begin{aligned}
& \sum_{t=i_{1}}^{i_{T}} r_{i_{1}, t} g_{t}^{i}\left(\hat{x}^{i}, q, r\right)=\sum_{t=i_{1}}^{i_{T}} r_{i_{1}, t} g_{t}^{i^{\prime}}\left(\hat{x}^{i}, q, r\right) \text { for all } \hat{x}^{i} \in X^{i}, i \in \mathcal{I}, \\
& \sum_{i \in \mathcal{I}_{t}} g_{t}^{i}\left(x^{i}, q, r\right)+v_{t} b_{t+1}-b_{t} z_{t}=\sum_{i \in \mathcal{I}_{t}} g_{t}^{i^{\prime}}\left(x^{i}, q, r\right)+v_{t} b_{t+1}^{\prime}-b_{t}^{\prime} z_{t}^{\prime} \text { for all } t \in \mathcal{T}, \\
& z_{t+1}^{\prime}=v_{t} / r_{t, t+1} \text { for all } t \in \mathcal{T} .
\end{aligned}
$$

That is, at the original prices, $p$ and $p^{\prime}$ imply identical net tax functions (condition (4)); at the original prices and household choices, $p$ and $p^{\prime}$ imply identical government cash flows (condition (5)); and at the original prices, debt markets clear under the new policy (condition (6)). Then, under Assumptions 1 and 2, the policy $p^{\prime}$ together with the same price system $(q, r)$, debt prices $v$, household choices $\left\{x^{i}\right\}_{i \in \mathcal{I}}$, and firm choices also constitutes a competitive equilibrium.

Proof. Consider the situation under the old price system and the new policy: From Lemma 1 and condition (4), the change of policy does not affect household choices; condition (i) of a competitive equilibrium therefore is satisfied. From Assumption 2, firm behavior is not affected; condition (ii) of a competitive equilibrium therefore is satisfied. From condition (5), if the initial policy satisfied the government budget constraint, so does the new policy; condition (iv) of a competitive equilibrium therefore is satisfied.Since the change of policy does not affect production possibilities, and since firm and household choices remain unchanged, all resource/production possibilities constraints continue to be satisfied; condition (iii) of a competitive equilibrium therefore holds. Finally, from 
condition (6), debt markets clear such that condition (v) of a competitive equilibrium is satisfied. ${ }^{6}$ The old price system, debt prices, household choices and firm choices together with the new policy therefore constitute a competitive equilibrium.

Under the new policy, household savings adjust in order to neutralize the effect of the different timing of tax collections: the change in each household's savings is the mirror image of the changed timing of tax collections by that household. The aggregate change of household savings therefore corresponds exactly to the change in the government's deficit, leaving economy-wide savings unaffected.

Given that the initial debt levels under $p$ and $p^{\prime}$ are the same (which is necessarily satisfied under condition (4)), condition (5) can alternatively be expressed as

$$
v_{t}\left(b_{t+1}-b_{t+1}^{\prime}\right)=-\sum_{s=-\infty}^{t} \frac{\sum_{i \in \mathcal{I}_{s}}\left(g_{s}^{i}\left(x^{i}, q, r\right)-g_{s}^{i^{\prime}}\left(x^{i}, q, r\right)\right)}{r_{s, t}} \text { for all } t \in \mathcal{T} \text {. }
$$

Using (4), this implies that the change of the discounted outstanding debt across policies equals the negative of the change in gross taxes that have been paid by households surviving period $t$. In particular, in the special case of two-period lived households, we have

$$
v_{t}\left(b_{t+1}-b_{t+1}^{\prime}\right)=-\sum_{i \in \mathcal{I}_{t}^{\text {young }}}\left(g_{t}^{i}\left(x^{i}, q, r\right)-g_{t}^{i^{\prime}}\left(x^{i}, q, r\right)\right) \text { for all } t \in \mathcal{T} .
$$

As an application of Proposition 1, consider a representative agent model where the household values consumption and leisure, saves and borrows at the market interest rate, sells labor and capital services to firms, purchases consumption goods from firms, and lends funds to the government. Assumptions 1 and 2 therefore are satisfied, implying that tax collections may be shifted over the entire horizon of the economy without affecting the equilibrium allocation (except for government debt holdings) ${ }^{7}$ as long as the net tax function imposed on the representative household remains unchanged (see Bassetto and Kocherlakota, 2004). In particular, with non-distorting taxes, economic equivalence of two fiscal policies only requires constancy of the present discounted value of taxes under the two policies; this is the standard Ricardian equivalence result (see Barro, 1974).

With overlapping generations rather than a representative household, and under assumptions 1 and 2, Proposition 1 implies that a change in the timing of tax collections leaves the allocation unaffected as long as the net tax functions imposed on each cohort remain unchanged. In particular, certain debt-and-tax policies are economically equivalent to pay-as-you-go financed transfer policies. Consider an environment with two-period lived overlapping generations. Let $p=(g,(\mathbf{0}, \mathbf{1}))=((\tau, \sigma),(\mathbf{0}, \mathbf{1}))$ be a policy without government debt that supports a competitive equilibrium with price system $(q, r)$ and debt prices $v_{t}=r_{t, t+1}$. Here, $\tau$ denotes taxes levied on young workers (social security contributions) and $-\sigma$ denotes transfers paid to old households (social security benefits).

\footnotetext{
${ }^{6}$ Condition (6) and the assumption that debt prices remain unchanged is stronger than needed. In general, $v^{\prime}$ may differ from $v$ as long as $z^{\prime}$ correspondingly differs from $z$.

${ }^{7}$ In the following, we will often omit the qualification "except for government debt holdings," to save on space.
} 
Let $p^{\prime}=\left(\left(\tau^{\prime}, \sigma^{\prime}\right),\left(b^{\prime}, \mathbf{1}\right)\right)$ be another policy, with government debt, satisfying conditions $(4),(5)$ and (6), namely

$$
\begin{aligned}
& \tau_{i_{1}}^{i}\left(\hat{x}^{i}, q, r\right)-\tau_{i_{1}}^{i}{ }^{\prime}\left(\hat{x}^{i}, q, r\right)+r_{i_{1}, i_{2}}\left(\sigma_{i_{2}}^{i}\left(\hat{x}^{i}, q, r\right)-\sigma_{i_{2}}^{i}{ }^{\prime}\left(\hat{x}^{i}, q, r\right)\right)=0 \text { for all } \hat{x}^{i} \in X^{i}, i \in \mathcal{I}, \\
& \sum_{i \in \mathcal{I}_{t}} \tau_{t}^{i}\left(x^{i}, q, r\right)+\sigma_{t}^{i}\left(x^{i}, q, r\right)-\tau_{t}^{i^{\prime}}\left(x^{i}, q, r\right)-\sigma_{t}^{i^{\prime}}\left(x^{i}, q, r\right)=r_{t, t+1} b_{t+1}^{\prime}-b_{t}^{\prime} \text { for all } t \in \mathcal{T}, \\
& z_{t+1}^{\prime}=1 \text { for all } t \in \mathcal{T} .
\end{aligned}
$$

Proposition 1 then implies that for any pay-as-you-go social security policy $((\tau, \sigma),(\mathbf{0}, \mathbf{1}))$, there exist economically equivalent policies relying on taxes, transfers, and explicit debt (see, e.g., Sargent (1987) for the case without distortions and Rangel (1997) or Niepelt (2005) for the case with distortions). In particular, there exists an economically equivalent policy that involves no transfers, $\sigma^{\prime}=0$.

This last example provides an algorithm for translating certain social security policies in economically equivalent debt-plus-tax policies and convex combinations thereof.

Why do some authors arrive at the conclusion that social security is not equivalent to debt? Because they constrain policy instruments. Birkeland and Prescott (2007), for example, keep certain taxes unchanged after the change from a social security to a debt policy.

\section{Politico-Economic Equivalence}

Our aim in this section is to establish conditions under which the equivalence result of Proposition 1 extends to situations where $p$ is endogenous, i.e., chosen to maximize some political objective function. More specifically, we are interested in the conditions under which a policy $p^{\prime}$ constitutes an equilibrium outcome if $p^{\prime}$ is economically equivalent to another policy $p$ which itself constitutes an equilibrium outcome. By "constituting an equilibrium outcome" we mean that the policy is subgame-perfect: Policy choices in a given period maximize the objective of the political decision makers in that period, subject to the state variables inherited from the past, the anticipated response by future political decision makers, any restrictions on policy instruments as well as the condition that policy choices must support a competitive equilibrium.

To evaluate subgame-perfection, we have to explicitly model the sequential nature of political decision making. Let $\mathcal{D} \subseteq \mathcal{T}$ denote the set of periods in which political decisions are taken. Without loss of generality, we consider either $\mathcal{D}=\mathcal{T}$ or $\mathcal{D}=\{0\}$, that is, discretion or commitment respectively. Let $p_{t}, t \in \mathcal{D}$, denote the policy choice by the political decision makers in period $t \in \mathcal{D} ; p^{t}$ the policy choices by subsequent political decision makers; and ${ }_{t} p$ the choices by policy makers in previous periods. A policy $p$ can then be partitioned as $p=\left({ }_{t} p, p_{t}, p^{t}\right)$ for all $t \in \mathcal{D}$. Similarly, the allocation $x$ can be partitioned as $x=\left({ }_{t} x, x_{t}, x^{t}\right)$ for all $t \in \mathcal{D}$ where ${ }_{t} x, x_{t}$, and $x^{t}$ denote private sector choices prior to, during, and after period $t$, respectively. We assume that, if political decision makers move in a given period, they do so before the private sector. We also assume that taxes are functions of current and past household choices only, to be consistent with sequential political decision making. 
Different degrees of commitment are not only reflected in the set of periods when policy choices are made, $\mathcal{D}$, but also in the set of policy actions available to political decision makers in period $t \in \mathcal{D}, \mathcal{P}_{t}$. Let $\mathcal{P} \equiv \prod_{t \in \mathcal{D}} \mathcal{P}_{t}$. With commitment $(\mathcal{D}=\{0\})$, $\mathcal{P}_{0}=\mathcal{P}$ and the policy choice in the initial period comprises the complete sequence of policy instruments over time. Under discretion $(\mathcal{D}=\mathcal{T})$, the policy choice in each period determines the contemporaneous policy instruments. Finally, with partial commitment (to a subset of policy instruments over a limited duration of time), the policy choice in a given period determines some policy instruments that apply in subsequent periods.

In line with many papers in the literature, we allow for non-fundamental state variables of the type sustaining trigger strategies. In particular, we allow for the possibility that non-fundamental state variables in period $t, z_{t}$, as well as policy choices in that period affect the non-fundamental state variables in period $t+1$. If a trigger strategy is played, then $z_{t+1}=1$ iff $z_{t}=1$ and $p_{t}$ coincides with the prescribed value, and $z_{t+1}=0$ otherwise. If no trigger strategy is played, then $z_{t+1}=1$ independently of $z_{t}$ and $p_{t}$. In both cases, the initial value of the non-fundamental state variables is given by $z_{0}=1$. We denote the law of motion for $z$ by $z_{t+1}=f\left(z_{t}, \mathbf{1}_{\left[p_{t}=p_{t}^{p}\right]}\right)$, where $\mathbf{1}_{\left[p_{t}=p_{t}^{p}\right]}$ denotes the indicator function for the event that the actual policy choice, $p_{t}$, coincides with the prescribed policy choice, $p_{t}^{p}$.

Sequential decision making implies that policy choices in period $t \in \mathcal{D}$ are functions of the economy's history, summarized by the allocation and policy choices so far as well as the value of the non-fundamental state variables, $\left({ }_{t} x,{ }_{t} p, z_{t}\right)$. In line with Assumption 1 according to which household preferences do not directly depend on policy, we assume that the objective function maximized by political decision makers, $\Omega$, does not depend on policy or prices either, but only on $x$. (Of course, without this assumption, economically equivalent policies would generally not be politically equivalent.)

Assumption 3. The political objective function in period $t \in \mathcal{D}$ is given by $\Omega_{t}(x)$.

Because of Assumption 3, political decisions in period $t$ only depend on those specific elements of ${ }_{t} p$ (beyond ${ }_{t} x$ and $z_{t}$ ) which shape policy makers' constraints in period $t$. These elements are (i) committed government cash flows in period $t$ or later, and (ii) committed gross tax functions for each $i \in \mathcal{I}$ in period $t$ or later. Part (i) covers the committed amounts of debt repayment in period $t$ or later (to whoever submits the government bonds at maturity). Part (ii) covers the precommitted effect of tax policy in period $t$ or later on the budget sets of all households $i \in \mathcal{I}$ (who are still alive). We denote these two "commitment elements" of ${ }_{t} p$ by $\pi_{t}$. Formally, we have

Lemma 2. Under Assumption 3, policy choices in period $t \in \mathcal{D}$ are a function of $\left({ }_{t} x, \pi_{t}, z_{t}\right): p_{t}=p_{t}\left({ }_{t} x, \pi_{t}, z_{t}\right)$. Moreover, if $t+1 \in \mathcal{D}$, then policy choices in period $t+1$ and later are a function of $\left({ }_{t+1} x, \pi_{t+1}, z_{t+1}\right): p^{t}=p^{t}\left({ }_{t+1} x, \pi_{t+1}, z_{t+1}\right)$.

Proof.

Letting $f$ denote the description of a trigger strategy (including the set of nonfundamental state variables and the prescribed policy sequence), we call the tuple $(\mathcal{D}, \mathcal{P}, f)$ 
a policy arrangement. A politico-economic equilibrium conditional on a set of initial conditions ${ }_{0} x$ and a policy arrangement $(\mathcal{D}, \mathcal{P}, f)$ consists of a policy $p$, a price system $(q, r)$, debt prices $v$, household choices $x^{i} \in X^{i}$ for all $i \in \mathcal{I}$, and choices by firms and/or the rest of the world such that (i) $(q, r), v, x^{i} \in X^{i}$ for all $i \in \mathcal{I}$, and choices by firms and/or the rest of the world constitute a competitive equilibrium conditional on ${ }_{0} x$ and $p$; and (ii) the policy $p$ constitutes a political equilibrium conditional on the policy arrangement $(\mathcal{D}, \mathcal{P}, f)$. Formally, this means that, for all $t \in \mathcal{D}$,

$$
\begin{aligned}
p_{t} \in & \arg \max _{\hat{p}_{t} \in \mathcal{P}_{t}} \Omega_{t}\left({ }_{t} x, x_{t}, x^{t}\right) \\
\text { s.t. } & { }_{t} x, \pi_{t}, z_{t} \text { given, } \\
& \hat{z}_{t+1}=f\left(z_{t}, \mathbf{1}_{\left[\hat{p}_{t}=p_{t}^{p}\right]}\right) \text { with } p_{t}^{p}=p_{t} \text { if trigger strategy is "active", } \\
& \left(\pi_{t}, \hat{p}_{t}, \hat{p}^{t}\right) \text { supports }\left(\hat{x}_{t}, \mid h a t x^{t}\right) \text { with }\left\{q_{s}, r_{t, s}, v_{s}\right\}_{s \geq t} \text { conditional on }{ }_{t} x, \\
& \hat{p}^{t}=p^{t}\left({ }_{t+1} \hat{x}, \hat{\pi}_{t+1}, \hat{z}_{t+1}\right) \text { is subgame perfect. }
\end{aligned}
$$

With commitment, economic equivalence of two policies directly extends to the political sphere: If policy is chose once and for all, then if $p$ is a Ramsey policy, so is the economically equivalent policy $p^{\prime}$. Under discretion, in contrast, economic equivalence extend to the political sphere only under certain conditions. The following result specifies a sufficient set of such conditions:

Proposition 2. Consider a politico-economic equilibrium under discretion, conditional on the policy arrangement $(\mathcal{T}, \mathcal{P}, f)$, consisting of the policy $p$, the price system $(q, r)$, debt prices $v$, household choices $x^{i} \in X^{i}$ for all $i \in \mathcal{I}$, and choices by firms and/or the rest of the world. Suppose Assumptions 1, 2, 3 are satisfied.

Consider the policy $p^{\prime}$ that is economically equivalent to $p$, and the policy arrangement $\left(\mathcal{T}, \mathcal{P}^{\prime}, f^{\prime}\right)$ where $p^{\prime} \in \mathcal{P}^{\prime}$ and $f^{\prime}$ differs from $f$ only insofar as the prescribed policy under $f^{\prime}$ is given by $p^{\prime}$ rather than $p$.

Suppose that the following condition, condition (PE), is satisfied for all $t \in \mathcal{T}$, conditional on $\pi_{t}$ : For all $\hat{p}_{t}^{\prime} \in \mathcal{P}_{t}^{\prime}$ with associated $\hat{\pi}_{t+1}$ that supports (together with some continuation policy) the competitive equilibrium allocation $\left(\hat{x}_{t}, \hat{x}^{t}\right)$, there exists a $\hat{p}_{t} \in \mathcal{P}_{t}$ with same associated $\hat{\pi}_{t+1}$ that supports (together with some continuation policy) the same allocation $\hat{x}_{t}$.

Then, the policy $p^{\prime}$ and the same price system, debt prices, household choices, and choices by firms and/or the rest of the world also constitute a politico-economic equilibrium, conditional on the policy arrangement $\left(\mathcal{T}, \mathcal{P}^{\prime}, f^{\prime}\right)$.

Proof. Consider first the situation without active trigger strategies. Suppose policy makers in previous periods implemented the economically equivalent policy ${ }_{t} p^{\prime}$ and the private sector expected policy makers to continue choosing $p_{t}^{\prime}$ and $p^{t^{\prime}}$. By economic equivalence and the assumption that $p^{\prime} \in \mathcal{P}^{\prime}$, policy makers in period $t$ then face the constraints ${ }_{t} x$ and $\pi_{t}$, making the choice $p_{t}^{\prime}$ feasible. To see whether $p_{t}^{\prime}$ also is optimal, suppose to the contrary that $\hat{p}_{t}^{\prime}$ strictly dominates $p_{t}^{\prime}$, subject to the policy arrangement $\left(\mathcal{T}, \mathcal{P}^{\prime}, f^{\prime}\right)$ and the competitive equilibrium constraints. By condition (PE), given ${ }_{t} x$ and $\pi_{t}$, there exists a $\hat{p}_{t} \in \mathcal{P}_{t}$ with same associated $\hat{\pi}_{t+1}$ that supports (together with some continuation 
policy) the same allocation $\hat{x}_{t}$. However, since $p_{t}$ constitutes an equilibrium outcome, the policy choice $p_{t}$ dominates $\hat{p}_{t}^{\prime}$. This implies a contradiction. The policy choice $\hat{p}_{t}^{\prime}$ therefore cannot dominate the policy choice $p_{t}^{\prime}$.

With active trigger strategies, the law of motion for the non-fundamental state variables only depends on whether the actual policy choice differs from the prescribed policy choice or not. As far as the trigger strategy is concerned, the incentives of political decision makers' to implement the prescribed policies therefore are symmetric across the two policies.

\section{Applications}

In this section, we apply our previous to a series of papers in the literature on the political economy of social security. All the papers we consider restrict the government to run a balanced budget. We show that this restriction is unnecessary. In all papers, the same allocation is supported in politico-economic equilibrium if defaultable government debt is introduced. Sometimes, however, the equilibrium strategies supporting the equilibrium with debt are significantly more complex than those supporting the equilibrium without debt. These findings are useful from a modeling point of view as they suggest a tractable strategy for modeling politico-economic equilibria with debt. At the same time, however, our findings clarify the particularities and restrictive nature of the assumptions imposed in some models.

\subsection{Boldrin and Rustichini (2000)}

Boldrin and Rustichini (2000) model pay-as-you-go social security as the subgame perfect equilibrium outcome of a majority voting game in an OLG model with production and capital accumulation. As long as a social security system is in place, the median voter decides in each period whether to dismantle the system or not. In the former case the promised benefits are paid to the old; moreover the median voter may then choose a promised social security benefit to be paid to the elderly in the subsequent period. Boldrin and Rustichini (2000) show that if a reduction in savings strongly increases the future return on capital then there are equilibria in which social security is voted into existence and maintained.

The actions of each median voter are given by $\left\{a_{t}, \tau_{t}\right\} \in\{0,1\} \times[0,1]$, where $a_{t}$ refers to the decision on whether to honor promised benefits and $\tau_{t}$ is the proposed tax rate for the subsequent period. Given an infinite history of the game, for any pair of adjacent periods in the history, the effective tax rate in period $t, \tilde{\tau}_{t}$ is defined as $\tau_{t-1}$ if the medium voter in period $t-1$ chose not to dismantle the system. Otherwise, the effective tax rate is zero, providing incentives not to deviate from the prescribed strategy. ${ }^{8}$ Given a sequence of population growth rates and effective tax rates, the competitive economic equilibrium

\footnotetext{
${ }^{8}$ If $z_{t}$ is a binary variable that takes the value of 1 if in the period $t-1$ the median voter chose the prescribed policy $p_{t-1}^{p}$ and 0 otherwise, then the law of motion for $z_{t+1}$ is $z_{t+1}=\mathbf{1}_{[]}\left[a_{t}=p_{t}^{p}\right]$, and the effective tax rate is given by $\tilde{\tau}_{t}=z_{t} a_{t} \tau_{t-1}$.
} 
is well defined, as is the lifetime utility of each agent. Taking each generation of agents as a single player specifies a well-defined game with a political equilibrium that, under the conditions mentioned in the previous paragraph, supports a social security system.

Consider a policy with debt that is economically equivalent to the politico-economic equilibrium policy with social security. Now each period the median voter decides whether to default on outstanding debt. Honoring the debt allows the generational player to choose a tax rate for the current period and the amount of debt issued to be repaid next period. Even if it seems as though the generational player has two instruments to choose, the government's budget constraint means that one is redundant, and we take the current tax to be residually determined. Without loss of generality we could define the choice of government debt issued as the fraction of next period's debt repayments over the aggregate wage income, which along the economically equivalent policy is numerically equivalent to the social security tax rate. This makes the action set of players to be the same as before: $\left\{a_{t}, \sigma_{t}\right\} \in\{0,1\} \times[0,1]$, where the $\sigma_{t}$ refers to the debt issuance ratio just defined. Having the effective debt to wage bill repayments at time $t$ to be related to $t-1$ choices in the same was as in the social security games completely specifies the debt game. ${ }^{9}$ Economic equivalence implies that if a given policy sequence with social security supported a competitive equilibrium, the corresponding equivalent policy with debt will support the same competitive equilibrium. Furthermore deviations from the prescribed policies have the same effect on real allocations. Thus agents lifetime utilities would also be the same both along and off equilibrium. The proposed policy with debt that is economically equivalent would then also be politico-economic equivalent.

\subsection{Cooley and Soares (1999)}

Cooley and Soares (1999) also use a reputational argument to explain the introduction and maintenance of social security in politico-economic equilibrium. Unlike Boldrin and Rustichini (2000), each period after the initial one the median voter decides whether to dismantle the system or keep it in place. The first median voter chooses a constant social security tax rate, which is in effect until repealed. In our terminology the non-fundamental state variable $z_{t}$ takes the value 0 for all periods $s>t$ if the system is repealed at time $t$. The authors calibrate an economy with four-period lived agents, with a median voter of age two, to match some long-run features of the U.S. economy.

Given that the assumptions for economic equivalence hold, there is an equivalent economy with debt that implements the same real allocation as the economy with social security. In the debt economy, if debt has not been repudiated, each period taxes are collected on workers, outstanding debt is repaid and new debt is issued. In the first period the median voter uses the income thus collected to make transfers to the old. In the following period it uses the income to repay the outstanding debt issued in the first period and then transfers the remaining funds to the current old. After three periods there is no income left after rolling over the debt.

There is a life-cycle to debt holdings. Each period workers save the income gain from lower taxes into debt, rolling over any debt holdings they might have from the previous

\footnotetext{
${ }^{9}$ Thus the effective debt repayment to wage income is given by $\tilde{\sigma}_{t}=z_{t} a_{t} \sigma_{t-1}$.
} 
period. When they retire the income from debt holdings equals the income they would have received under social security. Since social security payments were funded by a constant tax rate on labor income, debt repayments will be a constant share of aggregate wages. If the economy is not in steady state this implies that taxes and debt issues are time varying. To see this, we analyze a simplified version of Cooley and Soares's (1999) model where each cohort has measure one (i.e. there is no population growth), labor is supplied inelastically, and workers have the same productivity, normalized to one. The life cycle of debt implies

$$
b_{t+1}^{i}=R_{t} b_{t}^{i-1}+\left(\tau-\tilde{\tau}_{t}\right) w_{t}
$$

where $b^{i}$ denotes debt holdings of agents of age $i, \tau$ is the social security tax rate, $\tilde{\tau}$ is the tax rate when debt is used for intergenerational transfers. $R$ and $w$ are the interest rate and wage rate respectively.

In the initial period, at time $t$, the old receive a transfer $T_{t}$ that is equivalent to the one received under social security: $3 \tau w_{t}$ (there are three workers per retiree, all have the same labor income, and pay the same social security tax rate). This is funded out of taxes collected on workers and debt issues

$$
3 \tau w_{t}=T_{t}=3 \tilde{\tau}_{t} w_{t}+\sum_{i=1}^{3} b_{t}^{i}
$$

Of course in the first period all workers will buy the same amount of debt, that is equal to the savings in labor taxes: $b_{t}^{i}=\left(\tau-\tilde{\tau}_{t}\right) w_{t}$. In the second period, debt holdings will become heterogeneous as newborn workers demand debt for the first time and workers in their second and third periods of life will be accumulating past and present tax savings into debt. In this period the current retirees are paid for their debt holdings and receive a lump sum transfer $T_{t+1}$ satisfying

$$
3 \tau w_{t+1}=R_{t+1} b_{t}^{3}+T_{t+1}=3 \tilde{\tau}_{t+1} w_{t+1}+\sum_{i=1}^{3} b_{t+1}^{i}-R_{t+1} \sum_{i=1}^{2} b_{t}^{i} .
$$

In the third period there is still the need for a transfer to supplement debt returns in order to give retirees the same income as under social security. But afterwards, for periods $j>2$, the following relation must be satisfied by debt holdings and tax rates,

$$
3 \tau w_{t+j}=R_{t+j} b_{t+j-1}^{3}=3 \tilde{\tau}_{t+j} w_{t+j}+\sum_{i=1}^{3} b_{t+j}^{i}-R_{t+j} \sum_{i=1}^{2} b_{t+j-1}^{i} .
$$

Dividing by aggregate wages, we have

$$
\tau=\frac{R_{t+j} b_{t+j-1}^{3}}{3 w_{t+j}}=\tilde{\tau}_{t+j}+\frac{\sum_{i=1}^{3} b_{t+j}^{i}}{3 w_{t+j}}-\frac{R_{t+j} \sum_{i=1}^{2} b_{t+j-1}^{i}}{3 w_{t+j}} .
$$

It is clear from relations (8) and (9) that although debt repayments are a constant fraction of aggregate wages, unless the economy is in a steady state, tax rates and debt issues relative to wages are not constant. 
Incentives to default on debt are the same as the incentives to repeal social security. Every period the median voter, though she paid lower taxes in the previous period, foresees defaulting on debt as raising her burden up to the level that is equivalent to having paid the $\operatorname{tax} \tau$ in the previous period. Having described the economic equivalent debt economy it is trivial to show that there is a trigger strategy equilibrium that supports it. It just amounts to characterizing the prescribed policy choice $p_{t}^{p}$, appropriately keeping track of the corresponding tax rates and debt issues that guarantee the necessary debt repayments, and defining the law of motion of the trigger strategy, $f(\cdot)$ in accordance. But the fact that the prescribed policy is more complex than the simple policy under social security - a constant tax rate - hints that restricting policy under social security to choosing a constant tax rate has welfare costs if prices are affected by policy, as is the case in Cooley and Soares's (1999) model.

\subsection{Forni (2005)}

Forni (2005) finds that a social security can be sustained as a politico-economic equilibrium even if policies are restricted to be Markov perfect subgame equilibria, i.e. in the absence of reputational state variables. In his setup if the median voter expects that future social security benefits are a decreasing function of aggregate capital, then it might be possible to sustain a positive tax rate today. He characterizes politico-economic equilibrium in closed-form and finds multiple expectational equilibria. The policy function takes the form,

$$
\tau(k)=\frac{\alpha}{1-\alpha}\left[C k^{-\frac{1+\beta \alpha}{1+\beta}}-1\right]
$$

We will now relate this outcome to the one in an economy with debt. With $v_{t} b_{t}$ being the per-capita real debt issued at time $t, r_{t}$ the gross interest rate on outstanding debt paid at time $t$, and $1+n$ the gross rate of population, economic equivalence implies that the following must hold (where $k_{t}$ is the capital per-workers determined by $t-1$ savings),

$$
\frac{v_{t-1}\left(b_{t-1}, k_{t}\right) b_{t-1} r_{t}\left(k_{t}\right)}{w_{t}\left(k_{t}\right)(1+n)}=\tau\left(k_{t}\right)=\frac{\alpha}{1-\alpha}\left[C k_{t}^{-\frac{1+\beta \alpha}{1+\beta}}-1\right]
$$

Given Forni's (2005) assumption of Cobb-Douglas production and the fact that in equilibrium the return on debt must be equal to the return on capital the previous expression can be rewritten to give,

$$
v_{t-1}\left(b_{t-1}, k_{t}\right) b_{t-1}=k_{t}\left[C k_{t}^{-\frac{1+\beta \alpha}{1+\beta}}-1\right]
$$

As long as expectations on future government policy, in this case repayment on outstanding debt, are consistent with this equilibrium relation for real debt issues, then the politico-economic equilibrium of this economy is the same as in the one with social security. In particular notice that in this case debt issues in real terms are not a monotonic function of capital, but an increasing function for low levels of capital and then a decreasing function after some threshold level of capital. 


\subsection{Gonzalez-Eiras and Niepelt (2008)}

Consider an environment with two-period lived overlapping generations. Let $p=(g,(0,0))=$ $((\tau, \sigma),(0,0))$ be a feasible policy without government debt that supports the allocation $x$ and the price system $q$. Here, $\tau$ denotes taxes levied on young workers (social security contributions) and $\sigma$ denotes transfers to old households (social security benefits). Let $p^{\prime}=\left(\left(\tau^{\prime}, \sigma^{\prime}\right),\left(b^{\prime}, b^{\prime}\right)\right)$ be another policy, with explicit government debt, satisfying

$$
\begin{aligned}
& \tau_{i_{1}}^{i}\left(\tilde{x}^{i}, q\right)-q_{i_{1}, i_{2}} \sigma_{i_{2}}^{i}\left(\tilde{x}^{i}, q\right)=\tau_{i_{1}}^{\prime i}\left(\tilde{x}^{i}, q\right)-q_{i_{1}, i_{2}} \sigma_{i_{2}}^{\prime i}\left(\tilde{x}^{i}, q\right) \text { for all admissible } \tilde{x}^{i}, i \in \mathcal{I}, \\
& \sum_{i \in \mathcal{I}_{t}^{\text {young }}}\left(\tau_{t}^{i}\left(x^{i}, q\right)-\tau_{t}^{\prime i}\left(x^{i}, q\right)\right)-\sum_{i \in \mathcal{I}_{t}^{\text {old }}}\left(\sigma_{t}^{i}\left(x^{i}, q\right)-\sigma_{t}^{\prime i}\left(x^{i}, q\right)\right)-q_{t, t+1} b_{t+1}^{\prime}+b_{t}^{\prime}=0 \text { for all } t \in \mathcal{T} .
\end{aligned}
$$

It follows from Proposition 1 that $p^{\prime}$ is feasible and supports the same allocation (except for debt holdings) and price system as does $p$. The two policies therefore are equivalent: For any pay-as-you-go social security policy $((\tau, \sigma),(0,0))$, there exists a continuum of economically equivalent policies relying on taxes, transfers, and explicit debt. In particular, there exists a policy that involves no transfers.

Suppose that a politico-economic equilibrium featuring the social security policy $p=$ $((\tau, \sigma),(0,0))$ exists in the absence of commitment and non-fundamental state variables. The conditions in proposition 2 shows that any economically equivalent policy with explicit government debt, $p^{\prime}=\left(\left(\tau^{\prime}, \sigma^{\prime}\right),\left(b^{\prime}, b^{\prime}\right)\right)$, constitutes a politico-economic equilibrium as well since (due to the lack of commitment) policy makers face no additional constraints from past policy choices beyond those implicit in the allocation, and this is the same under $p^{\prime}$ than under $p$. Furthermore future policy is also a function only of the allocation as affected by current policy choices, $p^{t}=p^{t}\left(_{t+1} x\right)$.

Note that the policy with government debt necessarily constitutes a politico-economic equilibrium only if the economically equivalent social security policy constitutes such an equilibrium in the first place. In other words, if the political process supports intergenerational transfers through social security in spite of a lack of commitment then it also supports these transfers if they involve the issuance and redemption of government debt. Gonzalez-Eiras and Niepelt (2008) show that social security transfers are sustained in a politico-economic equilibrium with probabilistic voting although the political process lacks commitment. The above discussion implies that, equivalently, government debt will be honored in a politico-economic equilibrium with probabilistic voting and lack of commitment.

\section{Conclusion}

To be written.

\section{References}

Barro, R. J. (1974), 'Are government bonds net wealth?', Journal of Political Economy 82(6), 1095-1117. 
Bassetto, M. and Kocherlakota, N. (2004), 'On the irrelevance of government debt when taxes are distortionary', Journal of Monetary Economics 51(2), 299-304.

Birkeland, K. and Prescott, E. C. (2007), 'On the needed quantity of debt', Federal Reserve Bank of Minneapolis Quarterly Review 31(1), 2-15.

Boldrin, M. and Rustichini, A. (2000), 'Political equilibria with social security', Review of Economic Dynamics 3, 41-78.

Cooley, T. F. and Soares, J. (1999), 'A positive theory of social security based on reputation', Journal of Political Economy 107(1), 135-160.

Forni, L. (2005), 'Social security as Markov equilibrium in OLG models', Review of Economic Dynamics 8, 178-194.

Gonzalez-Eiras, M. and Niepelt, D. (2008), 'The future of social security', Journal of Monetary Economics (forthcoming).

Niepelt, D. (2005), Social security reform: Economics and politics, in G. Greulich, M. Lösch, C. Müller and W. Stier, eds, 'Empirische Konjunktur- und Wachstumsforschung', Rüegger, Zürich, pp. 181-195.

Rangel, A. (1997), Social security reform: Efficiency gains or intergenerational redistribution. Mimeo, Harvard University.

Sargent, T. J. (1987), Dynamic Macroeconomic Theory, Harvard University Press, Cambridge, Massachusetts. 